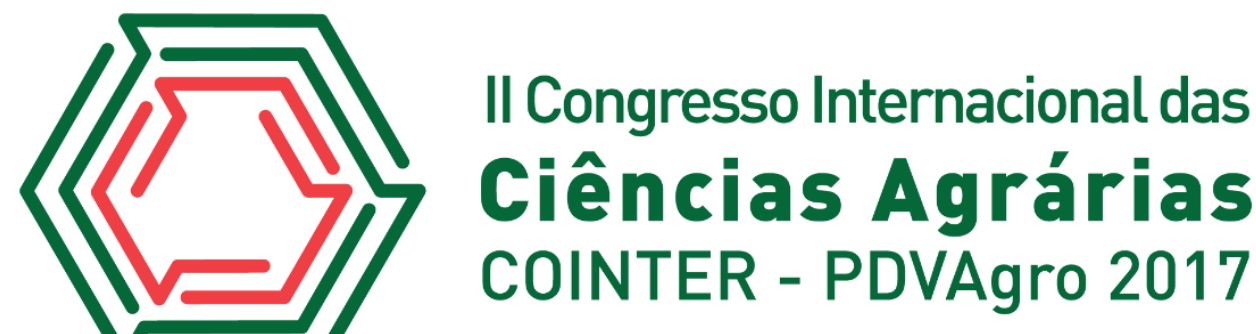

\section{CARACTERÍSTICAS ESTRUTURAIS DO CAPIM-MARANDU DURANTE O PERÍODO DE DIFERIMENTO}

\author{
Apresentação: Pôster
}

\begin{abstract}
Antonio Leandro Chaves Gurgel ${ }^{1}$; Ingrid Laíse Silvestre de Oliveira ${ }^{2}$; João Virgínio Emerenciano $\mathrm{Neto}^{3}$; Francisca Fernanda da Silva Roberto ${ }^{4}$ Gelson do Santos Difante ${ }^{5}$

\section{Introdução}

Pastos diferidos são caracterizados por conter elevado percentual de material morto e colmo em relação a lâmina foliar, isso ocorre por passar do ponto ideal de pastejo e tem como consequência baixo valor nutritivo do pasto. Aliado a isso durante o período de deferimento ocorre modificações na estrutura do pasto que afeta o comportamento ingestivo do animal, portanto animais mantidos em pastagens diferidas expressam desempenho modesto ou simplesmente mantêm seu peso corporal (SANTOS et al., 2009a), sendo necessário o uso de suplementação para complementar o valor nutritivo da forragem disponível e melhorar a eficiência no uso da forragem, a compreensão desses efeitos do períodos de diferimento sobre a estrutura do pasto e o pastejo pode resultar na geração de recomendações eficientes de manejo dos animais em pastagens diferida.
\end{abstract}

Diante disso objetivou-se avaliar a estrutura do capim-marandu durante o período de diferimento.

\section{Fundamentação Teórica}

Existem estratégias para disponibilizar forragem suplementar durante o período crítico do ano em recurso forrageiro, como: formação de capineiras de capim ou de cana-de-açúcar, ensilagem, fenação e diferimento do uso da pastagem. Estas estratégias são viáveis tecnicamente, porém o diferimento do uso da pastagem consiste em uma das estratégias de mais fácil adoção e, em geral, de

\footnotetext{
${ }^{1}$ Mestrando no Programa de Pós-graduação em Produção Animal, UAECA - UFRN, Macaíba, RN. Antonioleandro09@gmail.com

${ }^{2}$ Graduando em Zootecnia - UFRN, Macaíba, RN. ingrid-laise@hotmail.com

3 Professor do Programa de Pós-Graduação em Ciência Animal, UNIVASF, Petrolina, PE. joao_neto@zootecnista.com.br

${ }^{4}$ Mestranda no Programa de Pós-graduação em Produção Animal, UAECA - UFRN, Macaíba, RN. nandinha_roberto@yahoo.com.br

${ }^{5}$ Professor do Programa de Pós-graduação em Produção Animal, UAECA - UFRN, Macaíba, RN. gdifante@hotmail.com
} 
menor custo (SANTOS et al., 2009b).

A estratégia de diferimento da pastagem se baseia, dentre outros fatores, no acúmulo de forragem possível de ser obtido no terço final do período de crescimento do período chuvoso. Nesse período, dois processos ocorrem: o crescimento e o desenvolvimento (incluindo a senescência), (HODGSON, 1990). Durante o período de diferimento, também ocorre modificação na massa de forragem total, altura composição morfológica e relação de material vivo/morto, como consequência das mudanças nas condições do ambiente e da própria fenologia da planta forrageira, o que afeta o desempenho dos animais.

O conhecimento dessa modificação é fundamental, pois permite entender e inferir, por exemplo, os efeitos do período de diferimento sobre a persistência, a composição morfológica e o valor nutritivo do pasto diferido.

\section{Metodologia}

O experimento foi conduzido em área do Grupo de Estudos em Forragicultura (GEFOR), da Universidade Federal do Rio Grande do Norte, campus Macaíba-RN. O período experimental foi de 20/09/2016 a 23/03/2017. O clima da região é caracterizado como sub-úmido seco com excedente hídrico de maio a agosto (THORNTHWAITE, 1948). Os dados de temperatura foram obtidos do banco de dados do INMET e os de precipitação (Figura 1) por pluviômetro do tipo Ville de Paris em aço inox, instalado no local do experimento.

Figura 1. Precipitação pluvial mensal (P) e temperatura média (T) durante o período de setembro de 2016 a março de 2017

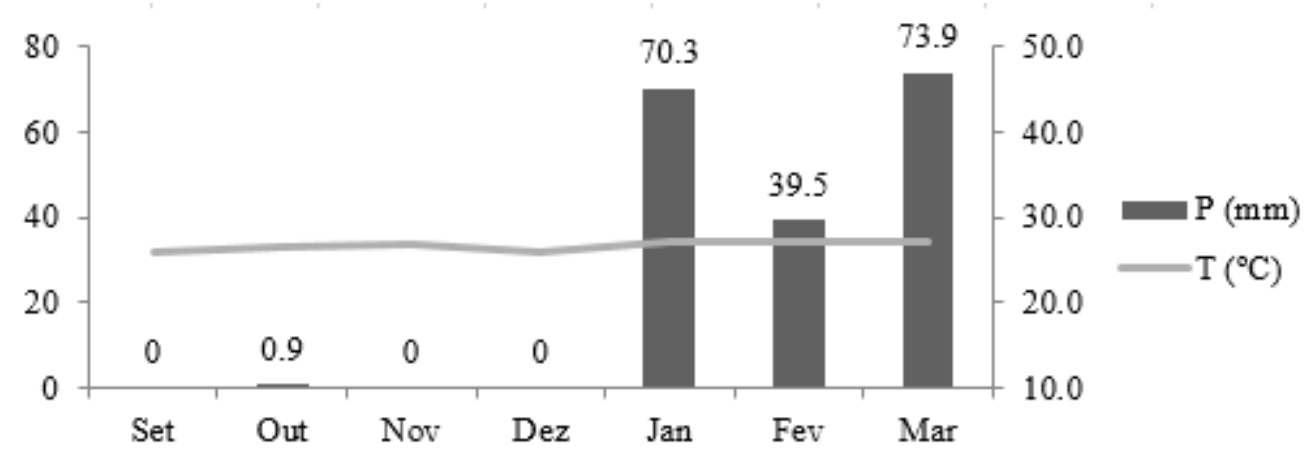

A área total de pastagem foi de 5,1 hectares, composta exclusivamente de Brachiaria brizantha cv. Marandu. O pasto foi vedado em meados de maio de 2016 e utilizado a partir de setembro do mesmo ano até março de 2017. O método de pastejo empregado foi o de lotação contínua com taxa de lotação variável. Como agentes de desfolhação foram utilizados 60 matrizes ovinas sem 
padrão racial definido (SPRD) com prenhes confirmada.

A cada 28 dias foram realizadas medidas de altura do pasto onde foi determinada por régua graduada em centímetro, foram realizadas 100 leituras por piquete, medidas na altura média da curvatura das folhas. A massa de forragem foi estimada pelo corte rente ao solo da forragem contida no interior de 21 áreas representativas no piquete, com o auxílio de quadrados de $1 \mathrm{~m}^{2}$. Desta foram retiradas sub-amostras representativas para a determinação da massa de forragem, de lâminas foliares, de colmo (colmo + bainha), de material morto e a relação vivo/morto.

O delineamento adotado foi inteiramente ao acaso. Os dados obtidos foram submetidos à análise de variância e as médias dos meses comparadas pelo teste de Tukey, a 5\% de probabilidade.

\section{Resultados e Discussões}

Houve efeito $(\mathrm{P}<0,05)$ dos meses de avalição para todas as variáveis estruturais do pasto durante o período de diferimento. A altura do pasto foi maior no mês de setembro (Tabela 1), início do período de pastejo, devido o pasto ter ficado sem pastejo durante quatro meses proporcionou alongamento de colmo provavelmente devido o maior sombreamento na base das plantas, comum em pastos sob maior período de diferimento, após o início do pastejo ocorreu um rebaixamento até o retorno do período chuvoso, em função do consumo da forragem sem ocorrer o acúmulo da mesma, enquanto que em janeiro, fevereiro e março os maiores índices pluviométricos (Figura 1) explicam a recuperação na altura do pasto.

Tabela 1. Médias das variáveis estruturais do capim-marandu durante o período de diferimento. Fonte: própria

\begin{tabular}{lcccccccc}
\hline Variáveis & Set/16 & Out/16 & Nov/16 & Dez/16 & Jan/17 & Fev/17 & Mar/17 & CV\% \\
\hline Altura (cm) & $84,1 \mathrm{a}$ & $64,5 \mathrm{bc}$ & $60,5 \mathrm{c}$ & $51,6 \mathrm{~d}$ & $63,0 \mathrm{bc}$ & $62,7 \mathrm{bc}$ & $66,6 \mathrm{~b}$ & 20,9 \\
MFT (kg/ha) & $6506,6 \mathrm{ab}$ & $6504,6 \mathrm{ab}$ & $6572,17 \mathrm{ab}$ & $4965,1 \mathrm{~b}$ & $5969,5 \mathrm{ab}$ & $7336,6 \mathrm{ab}$ & $7853,9 \mathrm{a}$ & 22,4 \\
MLF (kg/ha) & $770,10 \mathrm{abc}$ & $494,9 \mathrm{~cd}$ & $174,8 \mathrm{~d}$ & $173,8 \mathrm{~d}$ & $649,3 \mathrm{bcd}$ & $1120,8 \mathrm{ab}$ & $1196,6 \mathrm{a}$ & 47,9 \\
MC (kg/ha) & $1931,7 \mathrm{a}$ & $1660,2 \mathrm{cb}$ & $1017,2 \mathrm{abc}$ & $547,7 \mathrm{c}$ & $732,3 \mathrm{c}$ & $1214,6 \mathrm{abc}$ & $895,0 \mathrm{c}$ & 40,4 \\
MMM (kg/ha) & $3499,0 \mathrm{~b}$ & $4823,8 \mathrm{bc}$ & $5325,5 \mathrm{bc}$ & $5723,7 \mathrm{a}$ & $4800,4 \mathrm{bc}$ & $3934,7 \mathrm{bc}$ & $4937,4 \mathrm{ab}$ & 24,1 \\
Relação V/M & $0,60 \mathrm{a}$ & $0,57 \mathrm{ab}$ & $0,22 \mathrm{c}$ & $0,19 \mathrm{c}$ & $0,29 \mathrm{c}$ & $0,43 \mathrm{abc}$ & $0,34 \mathrm{bc}$ & 40,8 \\
\hline
\end{tabular}

MFT: massa de forragem total; MLF: massa de lâmina foliar; MC: massa de colmo; MMM; massa de material morto; Relação V:M; relação vivo morto; CV: coeficiente de variação. Médias seguidas de letras distintas na linha diferem entre si pelo teste de Tukey $(\mathrm{P}<0,05)$.

Segundo Emerenciano Neto et al. (2017) existe alta correlação entre altura do dossel e massa de forragem total (MFT), porém, nesse trabalho a maior MFT foi encontrada no mês de março mesmo não apresentando a maior altura do dossel que foi observada em setembro. Isso provavelmente 
ocorreu devido o maior sombreamento na base das plantas, comum em pastos sob maior período de diferimento, o que pode ter inibido o perfilhamento, haja vista que a redução na intensidade luminosa é um dos fatores de ambiente que reduz o perfilhamento em gramíneas (SANTOS et al., 2010). De maneira semelhante, Sbrissia e Da Silva (2008) também verificaram que a densidade populacional de perfilhos diminuiu em pastos de Brachiaria brizantha cv. Marandu manejados com maiores alturas. Em março, a redução na altura do dossel forrageiro em função do pastejo, aumentou a incidência de luz na base da planta, isso juntamente com a maior disponibilidade de água no solo refletiu na maior massa de forragem total.

A maior massa de lâmina foliar foi observada no mês de março $(\mathrm{P}<0,05)$, devido a maior concentração de chuvas nesse período (Figura 1). A maior massa de colmo $(\mathrm{P}<0,05)$, foi observada no mês de setembro, explicado pelo o alongamento excessivo de colmo, provavelmente, durante o período de diferimento, o dossel do capim-marandu passou a interceptar $95 \%$ da luz incidente, ou seja, atingiu o índice de área foliar crítico. A partir desse estádio, inicia-se a competição por luz entre os perfilhos e, como resposta, ocorre o alongamento do colmo na tentativa de expor as folhas num plano mais alto no dossel (CARNEVALLI et al., 2006). A maior massa de material morto foi observada no mês de dezembro é resultado do acúmulo contínuo deste componente no período seco e não consumido no messes anteriores.

A maior relação vivo morto foi observada no mês de setembro $(\mathrm{P}<0,05)$, devido o pasto ter ficado vedado por quarto meses havendo um acúmulo de lamina foliar, Logo após o início do pastejo os animais selecionam preferencialmente a folha e rejeitando o material morto, ocasionando um comportamento contraio na proporção desses dois constituintes nos meses de menores precipitações, com o início das chuvas e consequente acúmulo de folha essa relação voltou a aumentar. Deve-se considerar que, em condições de pastagens diferidas, a senescência de tecidos vegetais é, geralmente, mais acentuada em razão do elevado período de diferimento normalmente adotado para garantir um estoque razoável de forragem para ser utilizado durante o período seco (SANTOS et al., 2010), para contornar essa situação deve-se adotar a suplementação visando maximizar a utilização da forragem de menor qualidade nesse período.

\section{Conclusões}

Durante o período de diferimento do pasto ocorre diminuição na altura, massa de forragem total e de lamina foliar e a relação vivo morto, em contra partida ocorre aumento nas massas de colmo e material morto nos meses com baixas precipitações caracterizando um período crítico para pastejo 
dos animais.

\section{Referências}

cARNEVALLI, R. A.; DA SILVA, S. C.; BUENO, A. A. O. et al. Herbage production and grazing losses in Panicum maximum cv. Mombaça under four grazing managements. Tropical Grasslands, v. 40, n. 3, p. 165-176, 2006

EMERENCIANO NETO, J.V.; DIFANTE, G.S.; LANA, A.M.Q. et al. Sward structure and herbage accumulation of massai guineagrass pastures managed according to pre-grazing heights, in the northeast of Brazil. Journal of Agricultural Science, v.9, p.155-163, 2017.

HODGSON, J. Grazing management. Science into practice. Essex: Longman Scientific and Technical, 1990.

SANTOS, M.E.R.; FONSECA, D.M.F. BALBINO, E.M. et al. Capim-braquiária diferido e adubado com nitrogênio: produção e características da forragem. Revista Brasileira de Zootecnia, v.38, n.4, p.650-656, 2009.

SANTOS, M.E.R.; FONSECA, D.M.F.; EUCLIDES, V.P.B. et al. Produção de bovinos em pastagens de capim-braquiária diferidas. Revista Brasileira de Zootecnia, v.38, n.4, p.635-642, 2009.

SANTOS, M.E.R.; FONSECA, D.M.F.; GOMES, V.M. et al. Estrutura do capim-braquiária durante o diferimento da pastagem. Acta Scientiarum. Animal Sciences, v. 32, n. 2, p. 139-145, 2010.

SBRISSIA, A. F.; DA SILVA, S. C. Compensação tamanho/densidade populacional de perfilhos em pastos de capim-marandu. Revista Brasileira de Zootecnia, v. 37, n. 1, p. 35-47, 2008.

THORTHWAITE, C.W. An approach toward a rational classification of climate. Geographic Review, v.38, p.55-93, 1948. 